\title{
Urban Regeneration and New Partnerships among Public Institutions, Local Entrepreneurs and Communities
}

\author{
Claudia Trillo', a \\ ${ }^{1}$ SOBE, University of Salford, UK, Maxwell Building, The Crescent, Salford M5 4WT \\ ac.Trillo1@salford.ac.uk
}

Keywords: Urban Regeneration, Civic Economics, CDC, Main Streets, BID.

\begin{abstract}
The paper aims at investigating how different approaches in the interaction among public institutions, (local) entrepreneurs and communities lead to better perform effective urban regeneration processes. At this aim, purposely selected urban regeneration programs undertaken in some neighbourhoods of Boston are discussed against a conceptual frame drawn from the civic economics theory, trying to unveil the potential of innovative forms of multiple actors' partnerships acting together to achieve urban regeneration goals. The paper demonstrates how both a conceptual shift of the role of private investors in partnerships for urban regeneration, capable to incorporate traditionally public- led goals into private duties, and a conceptual shift of public and private partnerships mechanisms, capable to incorporate not exclusively market-oriented values but also the value of reciprocity, can led to achieve: a) territorial concentration, obtained through place-based, community- based organisations enacting also central policies; b) continuity over time, obtained through the overlapping actions of multiplestakeholders organisations covering different goals and areas that complement each other.
\end{abstract}

\section{Civic Economics and Urban Regeneration}

The main goal of the paper is to demonstrate that innovative forms of partnerships involving public institutions, local entrepreneurs and communities can contribute to improve the outcomes, also in economic terms, of urban regeneration processes, by discussing a set of cases studies against the conceptual frame provided by the paradigm of civic economics. At this aim, purposely selected urban regeneration programs undertaken in some neighbourhoods of Boston are discussed against a conceptual frame drawn from the civic economics theory, by trying to unveil the potential of innovative forms of multiple actors' partnerships acting to achieve urban regeneration goals. The paper concludes that an added value does exist in those urban regeneration processes, that are able to activate a network of multiple stakeholders, including local entrepreneurs and communities. In so doing, it provides the larger planners and policy makers community with useful insights applicable to different international contexts.

The conceptual frame implemented to discuss the role of the principal agents of urban regeneration, i.e. the market, the community and the public institutions, is drawn by the theory developed within the communitarian approach and in the public good thinking, possible alternatives to the capitalistic approach to the market economy. In the last decades a considerable numbers of economists and social policy theorists challenged the dominant intellectual paradigm in economic sciences, i.e. the capitalism. Some of them can be grouped in the communitarian wave, some others in the economics of public good one. The common root of all these movements is the question whether or not can the individual represents an adequate point of departure for the analysis of economic phenomena, lagging the community and the society behind.

Although the seeds of a communitarian-oriented thinking date back to the 19th century, it was in the 1980s that a group of political philosophers started to systematically challenge the individualist liberalism. The initiative The Responsive Community stemmed in the 1990s from this emerging movement, focusing on the balance between individual and public good and on the best way to build the good society, by overcoming the strict dichotomy between state and market [1]. According to Etzioni ([2]:2), "the good society balances the state, the market and the community". In the communitarian approach, the community gains a specific economic role, by overcoming the crude 
individualism of a strictly market- led approach. Although the communitarian perspective has been often considered as an alternative to the liberalism, it can be demonstrated how first liberalism contained many elements of communitarian thinking [3].The communitarian approach reinforces the new-institutionalism paradigm with regard to the role played by the community in creating value within the community itself, because it recognizes the impact of relational values on economics.

The Industrial revolution that seems to be a milestone in the construction of a firm individualistic economic paradigm. According to Zamagni [4], it was only after the Industrial revolution that Jeremy Bentham explained the economic mechanisms through individual utility, thus leading market economics to change its purpose, which turns from being the "common" good to being the "total" good. In this framework, capitalism can be considered a specific form of market economics and not market economics in itself, while market economics may include elements of reciprocity. By recasting the issue of the value of reciprocity in urban regeneration through a communitarian and/ or a common good economics perspective, it is possible to build a conceptual frame capable to capture the reciprocity among communities, public and private agents. In this way, the traditional dichotomy private vs. public approach to urban regeneration (i.e., market-led and commercial-led vs community-led regeneration) can be overcome. Although hard criticism has been expressed by some authors [5] on the effectiveness of the community-led approach in urban regeneration processes, it has to be highlighted how it concerns more the operational aspects of the community-led tools implementation rather than the recognition of the community added value in itself.

The multitude of public agents together with the multitude of private agents are both different sides of a relational nexus (either communitarian, or based on the reciprocity concept), that allows to enrich the process of creation of value through multiple actors-led regeneration. A place-based approach to urban regeneration, through the concentration of actions on a target area of limited size, represents a potential means for enhancing the relational values through the proximity of actors. By allowing multiple actors, including local and central governments and local and external investors, to interact within a targeted area and to focus on precise and concrete goals, it is possible to spur the added value recognized by the new paradigm developed by the civic economics. Furthermore, the overlapping of different instruments that make the interaction among actors possible, makes the programs dealing less vulnerable to the inevitable gaps (of financial stream, of the organisational structure...) that usually happen alongside such long-lasting processes.

\section{Urban regeneration initiatives and different partnerships among public institutions, private entrepreneurs and communities}

Research Methodology. Being the research project aimed to investigate the potential of the interaction among multiple actors within urban regeneration processes, the multifaceted nature of the research object suggests that a holistic and comprehensive research approach is needed. In addition to it, the research design intends to make unexpected results to emerge, by approaching the research object not only for theory testing, but also for exploring new hypothesis to be potentially implemented during the research process itself. For these reasons, the Grounded Based Theory - GBT approach [6] is considered as the most appropriate to conduct the empirical analysis related to discover the findings of the research design. GBT allows researchers to capture the complexity of the research object and has high potential to support an inductive process of incremental adjustment of the research hypothesis. The case study methodology, whose rationale is strictly bounded to the GBT, appears as the most appropriate for conducting the empirical analysis for many reasons.

As Johansson ([7]: 4) observes, in some disciplinary field, such as architecture and planning, "the case study has a special importance", because the principal way of learning and discussing innovative ideas in these disciplines is through experience, i.e. it is based on an in depth descriptions of concrete cases. As Yin states ([8]: 4), "the case study is a method of choice when the phenomenon under study is not readily distinguishable from its context. Such a phenomenon may be a project or a program in an evaluation study. ... The inclusion of the context as a major part of a study, however, creates distinctive technical challenges ... (such as the fact that) the study cannot rely on a single data collection method but will likely need to use multiple sources of evidence". 
The construction of the research design pays particular attention to the criteria of selection of the case studies to be investigated. This latter represents a crucial step in order to guarantee reliability of the whole research design. Flyvbjerg([9]: 391) advocates the fundamental role of the case study approach, particularly in order to study urban environments. In so doing, he discussed the five common misunderstanding still sometime plaguing the case study research approach, challenging each of them as follows: (1) it may seem that "general, theoretical (context-independent) knowledge is more valuable than concrete, practical (context-dependent) knowledge", while on the contrary experts are those who collected a huge number of experiences, and not those who studied issues in theory; (2) it may seem unmanageable "to generalize on the basis of an individual case", while on the contrary any scientific discovery is potentially subjected to be falsified according to Karl Popper; (3) it may seem that "the case study is most useful for generating hypothesis, ... while other methods are more suitable for hypothesis testing and theory-building", while on the contrary generalisability does have the potential to be achieved through an appropriate selection of the cases, based on clear criteria; (4) it may seem that "the case study contains a bias..., a tendency to confirm the researcher's preconceived notion", while according to Popper again, it is falsification much more than verification which supports the findings reliability; and finally, (5) it may appear difficult "to summarize and develop general proposition and theories on the basis of specific case studies", but the suitability to be summarized does not belong to the richness of the reality, thus, it is much more up to the studies object and not to the method that a "thick" description is even desirable.

All the criticisms raised by Flyvbjerg are addressed in the construction of the research design, which is based on the two main steps: (1) construction of a conceptual frame aimed at assessing the role of multiple actors in urban development, that draws from tested hypothesis and consolidated theories; (2) selection of the case studies based on a preliminary investigation aimed at ensuring the appropriateness of the empirical data to the general investigation goals.

Following these general criteria, the conceptual frame drawn from the civic economics theory is discussed against purposely selected testing areas, characterized by the presence of significant interaction among public institutions, local entrepreneurs and communities. At this purpose, the city of Boston appeared as an ideal field of analysis, considering the long tradition in terms of advocacy planning that dates back to the $60 \mathrm{~s}$ (as excellently narrated by Gans [10]) and produced a vibrant urban community still active in terms of a considerable number of community-led initiatives [11]. Within the city of Boston four areas have been investigated, selected in order to analyse different types of formalized partnerships among public institutions, local entrepreneurs and communities: two Community Development Corporations, one Main Street organisation and one Business Improvement District. In legal terms, they are Non-Profit Organisations regulated under the Federal Internal Revenue Service laws - 501(c) organisations - and thus belonging to different categories in order to take advantage from the related tax exempt status.

The case studies have been investigated through field work based on an in-depth visual survey, fully documented by photographs and additional notes, and on a set of semi-structured interviews with key players of the regeneration process both selected through a preliminary desk analysis and through the snowball technique. Interviews and field work have been conducted throughout a 4 months period (February-April 2012) of observations, that included also participation in local neighborhoods planning events.

Discussion of the case studies. As anticipated, the city of Boston represents a very good context for analysing the interaction among multiple actors in urban regeneration, due to the long tradition first in terms of advocacy planning [10] and in terms of current planning approach, that gives communities a central role [11]. The interaction among public and not public actors involves a multitude of bodies, groups of interest and associations, that can be grouped in two major categories. The left hand cloud in the figure 1 below includes the principal public bodies involved in the urban regeneration processes considered for the purpose of the research, that are, from the Federal Government and the State of Massachusetts to the Boston Redevelopment Authority and to the further smallest planning authorities. The right cloud in the figure 1 includes together both those 
actors traditionally labeled as "private" stakeholders in the Public-Private Partnership (PPP) - led approach, that are Real Estates and private companies, and those actors that are not very often fully considered within the real estate dynamic of PPP in urban regeneration, i.e. the neighborhood associations, more important under the conceptual umbrella of the community-led urban regeneration field of studies. In the middle, some different instruments that can be implemented in order to serve the urban regeneration goals by allowing the different actors to interact are listed: from the Main Street initiatives to the Community Development Corporations, from the Business Improvement Districts to the more general tools of the Memorandum of Agreement. All of them, by investing financial and other resources, aim to generate, in different way, added value. Purpose of the case studies analysis is to unveil the potential added value related to the implementation of different instruments in relationship with the theory of civic economics, thus allowing researchers to come up with general conclusions, applicable to different international contexts and places.

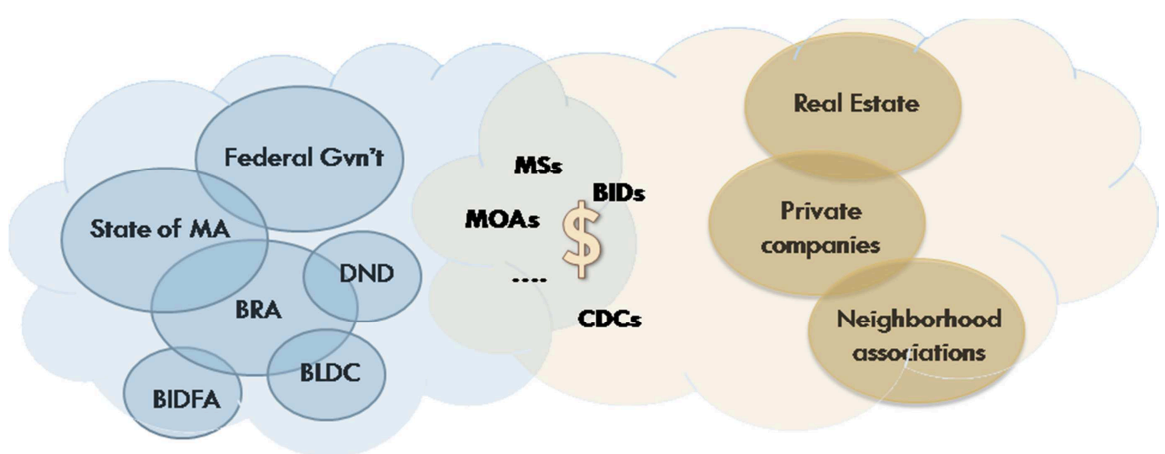

Fig. 1, Multiple players and instruments into the urban regeneration arena of Boston, MA

The first two cases that are considered for the purpose of the research are drawn from the Community Development Corporations (CDCs) implementation experience in Boston. A Community Development Corporation (CDC) is a nonprofit corporation serving an area that is economically disadvantaged. CDCs major topic is housing, although CDCs demonstrated capability to develop and deliver programs on small businesses, training, child care ([13]: 199). In the State of Massachusetts, CDCs are regulated under the Chapter 40 section 2. Nonprofit organisation can become community partners by being certified under the Chapter 40 section 2 , thus demonstrating that they are genuinely community based and actively engaged in community development work. Under the current MA legislation, community partners can apply through a competitive process to get tax credit allocation from $50.000 \$$ to $150.000 \$$ per year, capable to leverage from $100.000 \$$ to $300.000 \$$ for expanding housing opportunities, creating jobs, starting and growing local businesses, eliminating blight. A joined effort from multiple actors, from the Federal Government that provides tax credit, to the Boston Redevelopment Authority, that manages the applications, and finally to the private investors (local and external) attracted by the financial benefits provided by the public authorities, is put forward to achieve well-defined urban regeneration goals, in some cases on a specific area. According to Don Bianchi [14], most of the CDCs in the State of Massachusetts are geographically based, sometime their areas overlap. Their size vary a lot and the major issues tackled are: (1) housing development; (2) business development and (3) other services (e.g., foreclosure prevention). As visualised in the figure 2, CDCs become a sort of vehicle for allowing efforts from different actors of different scales to converge towards a selected area. It might also happen that the actions of different CDCs, operating in different fields on areas that can totally or partially overlap, end up in converging on the same target area. In so doing, if one of the initiatives goes through a stalemate phase, the revitalisation process in the area does not stop but is put forward by other or even by the same actors organised under the label of another instrument. 


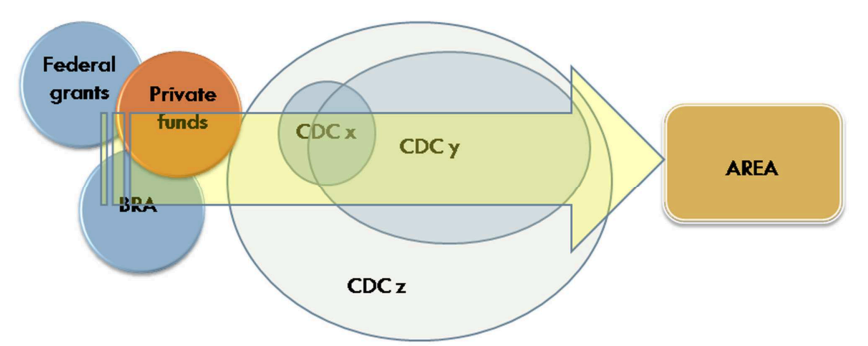

Fig. 2, Multiple players converge through CDCs towards target areas sometimes overlapping

According to Joe Krieger [15], in the context of the State of Massachusetts, CDCs support small business particularly through: (1) providing incubators, such as in the cases of JPNDC or Franklin; (2) providing training and advising and (3) providing LOANS (Treasury Dept, Housing Dept, Agriculture Dept, SBA have programs for loans through CDCs). CDCs are really very different, although the definition by law is one. However, a common feature of all CDCs is that with a small amount of money big results can be achieved. Small business are usually not able to get a modest loan from the bank not because they are not able to produce a profit, but for various reasons not related to their financial capability (language barriers, low skills, or just because the profit for the banks with small businesses is low). CDCs allow to put into reality a fine grain of local enterprises, capable to stir the potential of the community in terms of entrepreneurship. The relational network embedded within the spatial location (typically, the neighborhood), allows to maximize the potential of civic economics values throughout the urban regeneration process. As stated again by Joe Krieger [15], at the Massachusetts Association of Community Development Corporation, the major association of mission-driven community development organizations in the State of Massachusetts [16], "they believe that CDCs have to be rooted in a place (a neighborhood, a city), they have to be place-based, and that, in order to have a great neighborhood, a neighborhood organization is needed to involve residents and to have an in-depth understanding of its unique aspects".

Examples of what said above can be considered the long-lasting story of two CDCs located in different areas of Boston, the Codman Square Neighborhood Development Corporation (NCD) and the Jamaica Plain Neighborhood Development Corporation (JPNDC). The Codman Square NDC operates in an area surrounding Codman Square and South Dorcester, characterised by the strong presence of Latin and black minorities. The main goals are creating housing and commercial spaces that are safe, sustainable and affordable and to promote financial and economic stability for residents through a broad range of services and activities. Through an intense community planning activity, several achievements have been made in the last years, including renewing historical landmark buildings, building affordable housing, supporting job creation in the area. The photo survey shows a renewed historical building in the area, a local business run by minority residents, the offices of the NDC where participated planning sessions use to take place and an affordable housing building promoted by the NDC.
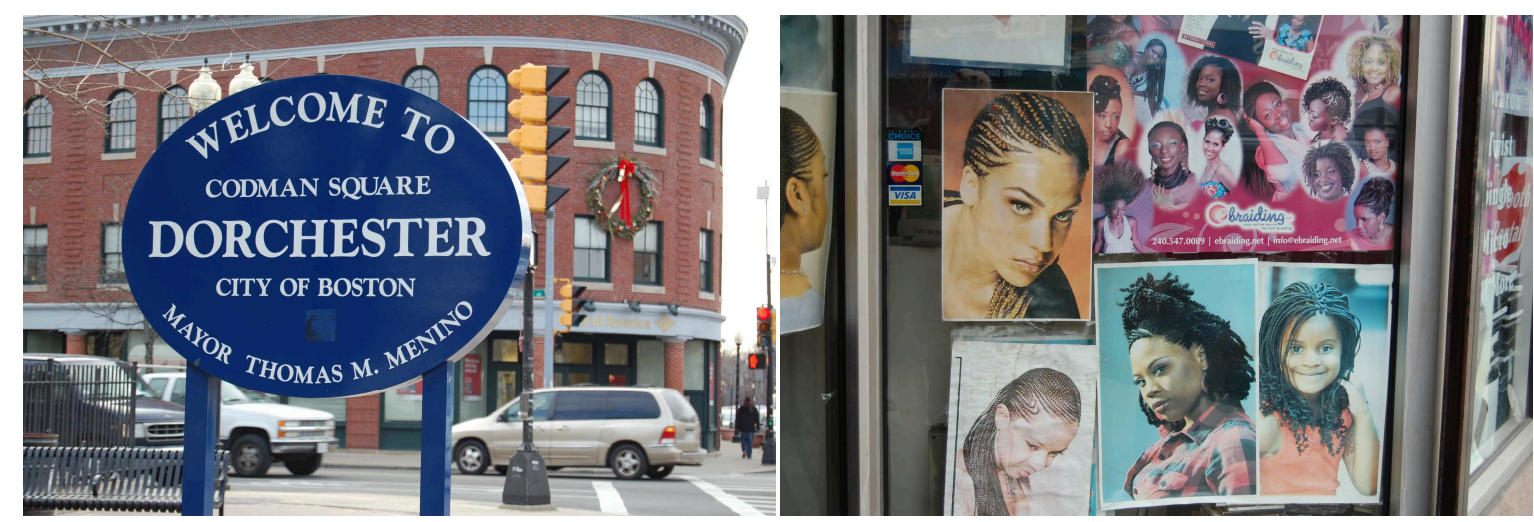


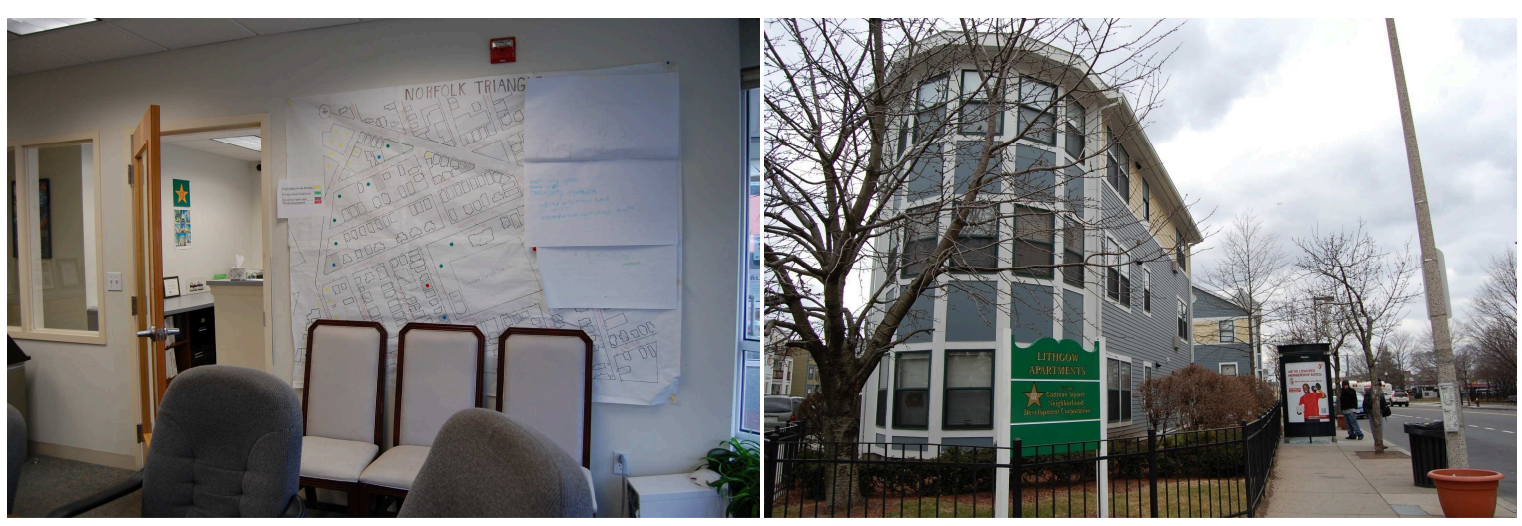

Fig. 3, 4, 5, 6. Photo survey from the Codman Square NDC (author's pictures, 2012)

The JPNDC operates in an area characterised by the presence of a former industrial building, whose history deeply impacted on the fortune and decline of the area, the so-called Brewery. The industrial legacy of the past is still visible in the red-bricks old factory, while the production of beer, once located at the heart of the area and providing residents with job places that ensured socio-economic stability to the neighborhood, is now over. One of the biggest achievement of the JPNDC was first purchasing the Brewery building and then turning it into a small enterprises incubator, where business applying to locate are selected also taking into account whether or not they express a need from the local community, in particular from weak groups such as minorities, women and young people. The photo survey shows the good conditions of the urban environment following the redevelopment strategy implementation in the area, the Brewery building after having been restored, a list of local businesses run within the Brewery incubator and a community planning meeting focusing on the issues of the neighborhood. Both the CDCs cases show how a place-based and community-led redevelopment strategy may be capable to overcome not only the silo-approach in urban regeneration but also the traditional private $v s$ public dichotomy that prevent from considering private stakeholders as capable to contribute to perform public goals.
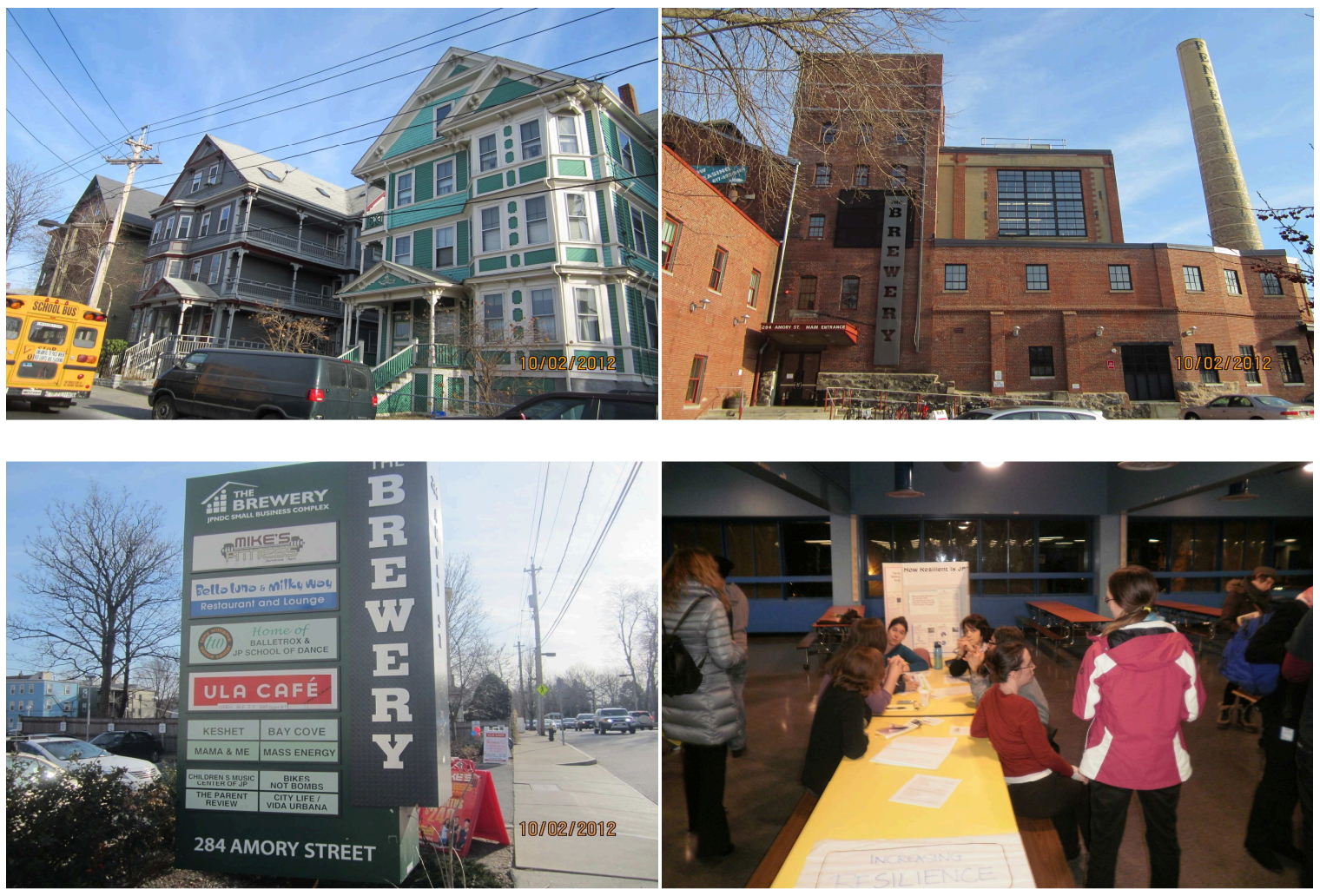

Fig. 7, 8, 9, 10. Photo survey from the JPNDC (author's pictures, 2012) 
The third case that is considered for the purpose of the research is drawn from the Main Street program implementation in Boston. The Main Street program is a national program launched in the 1970s by the National Trust for Historic Preservation to revitalise the historic built environment through a holistic approach based on design, promotions and socio-economic revitalisation. As visualised in the figure 11, Main Streets channel national funds to focused target areas through local authorities, thus encouraging private investors to contribute to urban revitalisation thanks to their trust in better perspectives for the area. The Main Street program was brought to Boston in 1983 by the Major Thomas Menino, that still plays an important role in the success of the initiative. Today, the City of Boston still commits a considerable part of its federal budget from the Community Development Block Grant to the Boston Main Street Program. Main Streets rest on a very small organisational structure. Only executive directors are paid (hired by the local Board), others are volunteers. The overall budget is nearly about $30.000 \$$ per year for each Main Street to cover mainly administrative costs, rent and office supply. Again, we are in presence of a very low budget that is run to perform urban regeneration goals; however, the results that can be appreciated by visiting neighborhoods where the Main Street program has been run for some year are almost extraordinary, as even such a limited amount of money allows to gear an enterprise- friendly environment and to attract private new businesses in the area, contributing to revitalise the socio-economic context.

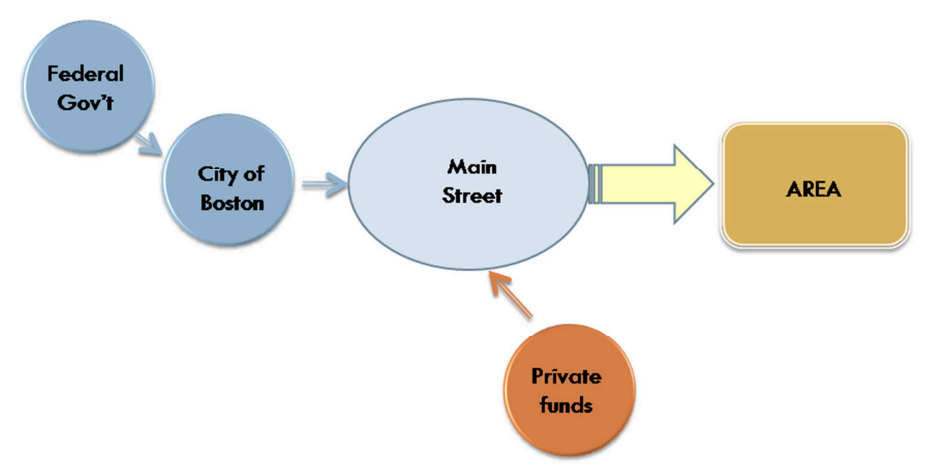

Fig. 11. Multiple players converge through Main Streets towards target areas

As an example, it is here described the case of Washington Gateway Street Main Street, located close to the city centre. At the time when the program started to be run, the area lagged in an almost blighted state, although the urban landscape in itself was very interesting, characterised by the presence of historical and heritage buildings that made (and still make) the urban environment vivid and rich. The implementation of the Main Street program in the area allowed to start up a very effective process of urban regeneration. Nowadays, while crossing Washington Street, it is possible to appreciate the great number of new businesses in the area, lot of them locally rooted or run by entrepreneurs from minority groups, as well as it is possible to admire very well kept community gardens right in the heart of the neighborhood that testify the high level of engagement of the community in maintaining the urban environment. By the interview conducted with Jennifer Effron [17], responsible for running the Main Street program at Washington Gateway, it clearly emerged how the major goal for the program was "to make the place a walking destination..." by eliciting "the character of the area". 

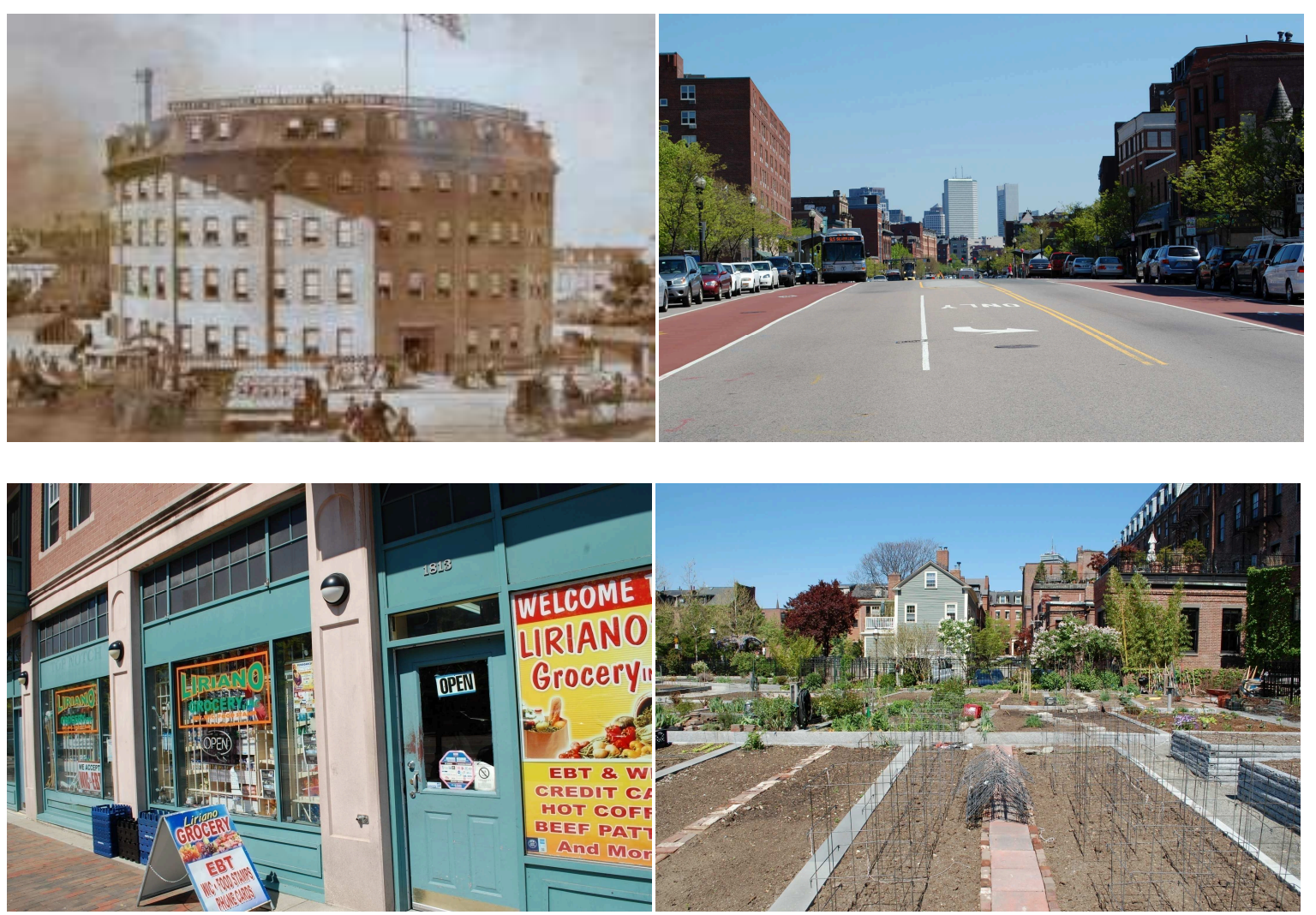

Fig. 12, 13, 14, 15. Photo survey from the Main Street Washington Gateway (author's pictures, 2012)

The fourth case that is considered for the purpose of the research is the only Business Improvement District (BID) set up in Boston, i.e. the Downtown BO. BIDs are financing mechanism used by property owners and merchants to manage improvements within areas with a specific major destination (retail, commercial, industrial). They band together to collect money, that returns to the BID in form of supplemental services, such as promotions, cleaning and security services, maintenance, sanitation, special events and in form of capital improvements, such as special lighting, street furniture, trees, signage. As visualised in the figure 16, the BID is a sort of self-promoted initiative led by the local businesses in a certain area and supported by the local authority.

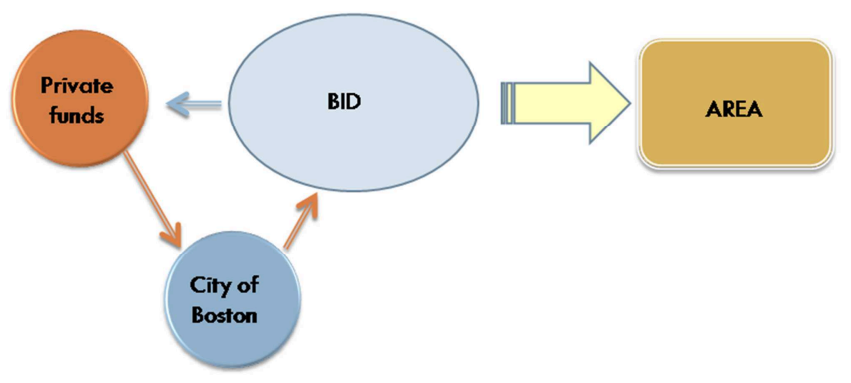

Fig.16. Multiple players converge through BIDs towards target areas

According to Steve Brookes [19], in the Downtown BO exclusively property owners tax dollars pay for the program; the fee is paid to the city and the office of the BID delivers the additional services. The photo survey in the figures below show first two images of the urban context of the BID, and then two services provided by the Downtown BID (cleaning services and the so-called "ambassadors", i.e. volunteers that welcome and orient people within the area). From the mentioned interview conducted with Steve Brookes, it also emerged that when the BID started to be run, people were very hesitant, while now there are people in the close neighborhoods such as Chinatown, 
Theatre District, Cambridge, North Boston, who are looking at Boston Downtown and get more and more interested in the experience. He furthermore believes that the stronger achievement of the Downtown BO experience is its role in terms of advocacy, because properties see the advantages of being part in the BID in order to be more effective when interacting with local Authorities and other counterparts. The importance of relational values beyond the merely financial advantages that can be achieved through a joined-up management of the urban regeneration process clearly emerges also in the case of Downtown BO.
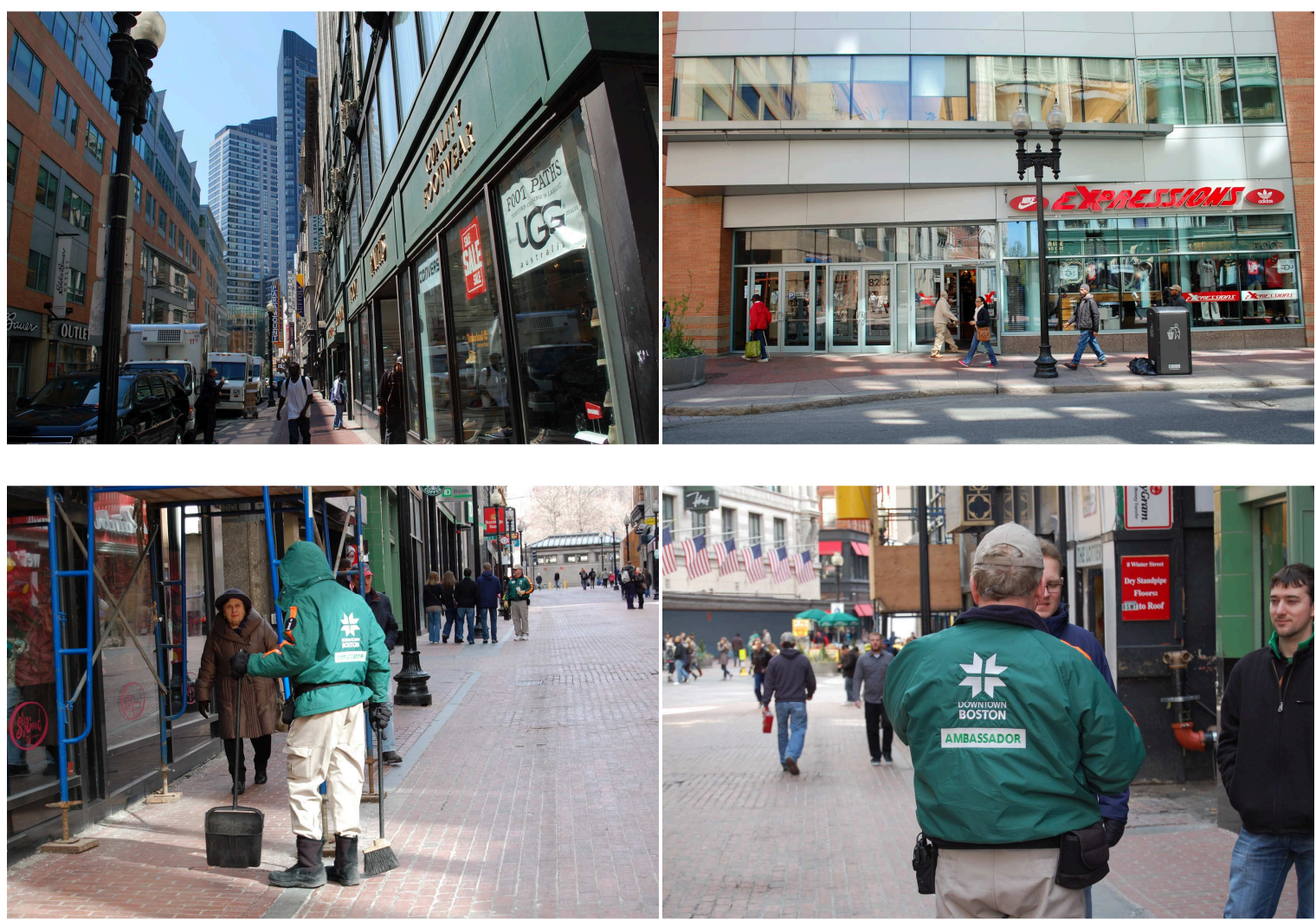

Fig. 17, 18, 19, 20. Photo survey from the Downtown BO BID (author's pictures, 2012)

Findings from the case studies. To sum up, common features that emerge from all the selected case studies are: (1) they all performed a clear spatial concentration of actions through a place-based and community-led organisation, capable to enact also the centrally promoted programs with a view to the uniqueness of the place; (2) a central role is played by the same mentioned organisations in planning and delivering programs and related services; (3) public initiatives performed in the areas were focused not only on acting as financial leverage but also on spurring the community added value. By overcoming the traditional dichotomy between public $v s$ private actors, still plaguing the effectiveness of many urban regeneration policies and programs, the case studies prove the potential of a double conceptual shift as follows: (1) a conceptual shift of the role of private investors in partnerships for urban regeneration, capable to incorporate traditionally public- led goals into private duties, and (2) a conceptual shift of public and private partnerships mechanisms, capable to incorporate not exclusively market-oriented values but also the value of reciprocity.

Results from the case studies led to conclude that they both can led to achieve: (a) territorial concentration, obtained through place-based, community- led organisations enacting central policies; (b) continuity over time, obtained through the overlapping actions of multiple- stakeholders organisations covering different goals and areas that complement each other. The general theory embedded in the conceptual frame implemented through the discussion of the empirical cases allows generalisabilty of these findings in the larger international context, thus producing insights applicable to different places worldwide. 


\section{Conclusions}

This paper was aimed at demonstrating the potential of the conceptual paradigm of civic economics within urban regeneration processes. At this aim, it first reflected on how far civic economics can be translated into urban regeneration terms, and then discussed some case studies against this conceptual frame. Through an in-depth discussion of some case studies, it has been proved the added value of an innovative approach in building partnership within urban regeneration processes, based on a role of private actors in partnerships for urban regeneration, capable to cover also traditionally public roles and to maximise cooperation in the process.

Both the above mentioned conclusions match the directions suggested by recent studies in the economic and social science fields. As stated by Akula ([20]: 158 and 172), it is time to push a new approach for the traditional "third way", that is the "end of poverty through profitability", achieved through a shift from the concept of non profit to the concept of "for-profit companies for poor" through microfinance, interpreted as a sort of bottom-up and widespread social activation for the socio-economic growth capable to involve every single, although minuscule, actor. The potential of cooperation among multiple actors has been recently underlined by Nowak ([21]: 284) in his analysis of the so called "super-cooperators", that are actors particularly talented in terms of sharing, team working and demonstrating an ethically correct behavior. Possible future researches could even attempt to recast the way of building the socio-economic context through the neo-institutional approach in terms of super-cooperators arena, thus providing an innovative instrument to interpret and evaluate the role and mutual interactions of multiple actors within urban regeneration processes.

\section{Acknowledgements}

The research results discussed in this paper have been developed within the research program "CLUDs" financed under the 7th European Research Framework - Marie Curie IRSES actions. The author thanks the anonymous reviewers for their valuable comments.

\section{References}

[1] A. Etzioni (ed.):The Essential Communitarian Reader, Lanham, Rowman and Littlefield Publishers, Inc. (1998)

[2] A. Etzioni: The Road to the Good Society, New York, Basic Books (2001)

[3] T.A. Spragens: Communitarian Liberalism, in: Etzioni A. (1995) (ed.) New Communitarian Thinking, Charlottesville and London: University Press of Virginia (1995)

[4] S. Zamagni: L'economia del bene comune, Roma, CittàNuova Editrice (2001)

[5] R. Stoeker: The CDC model of urban redevelopment: a political economy critique and an alternative, in: Journal of Urban Affairs, Vol. 19, $\mathrm{N}^{\circ}$ 1, (1997), pp. 1-22

[6] B. Glaser, A. Strauss: The Discovery of the Grounded Theory: Strategies for qualitative research, Chicago, Aldine (1967)

[7] R. Johansson: Case Study Methodology, Key-note speech at the International Conference "Methodologies in Housing Research" organised by the Royal Institute of Technology in cooperation with the International Association of People- Environment Studies, Stockholm, 22-24 September 2003

[8] R. Yin: Case Study Research: Design and Methods, (Fourth edition), Thousand Oaks, London, New Delhi: Sage (2009)

[9] B. Flyvbjerg: Five misunderstandings about case-study research, in: Qualitative Inquiry, 12(2),(2006), pp. 219-245

[10] H. Gans: The Urban Villagers, The Free Press, New York (1962) 
[11] Information on http://www.bostonredevelopmentauthority.org/planning/community- planning, accessed February 2014

[12] Information on http://www.irs.gov/Charities-\&-Non-Profits/Charitable-Organizations /Exemption-Requirements- Section-501(c)(3)-Organizations, accessed March 2014

[13] B. Cullingworth: Town and Country Planning in the UK, Routledge, London (2002)

[14] Interview with Don Bianchi, MACDC, 25 ${ }^{\text {th }}$ April 2012

[15] Interview with Joe Krieger, MACDC, $1^{\text {st }}$ May 2012

[16] Information onhttp://www.macdc.org/,accessed February 2014

[17] Interview with Jennifer Effron, Washington Gateway, 23 ${ }^{\text {rd }}$ April 2012

[18] Interview with Steve Brookes, $23^{\text {rd }}$ April 2012

[19] V. Akula:A fistful of rice, Harvard Business Review Press, Boston, MA (2011)

[20] M. Nowak: Supercooperators, New York, Free Press (2011) 